\title{
Acute Kidney Injury in Western Countries
}

\author{
Josée Bouchard ${ }^{a}$ Ravindra L. Mehta ${ }^{b}$

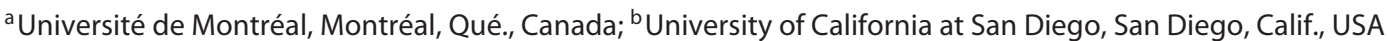

\section{Key Words}

Acute kidney injury · Epidemiology · Mortality · Outcomes ·

Renal replacement therapy

\begin{abstract}
Background: Acute kidney injury (AKI) is frequent and is associated with poor outcomes, including increased mortality, higher risk of chronic kidney disease, and prolonged hospital lengths of stay. The epidemiology of AKI mainly derives from studies performed in Western high-income countries. More limited data are available from Western low-income and middle-income countries (LMICs) located in Central and South America. Summary: In this review, we summarize the most recent data on the epidemiology of AKI in Western countries, aiming to contrast results from industrialized high-income countries with LMICs. The global picture of AKI in LMICs is not as well characterized as in the USA and Europe. In addition, in some LMICs, the epidemiology of AKI may vary depending on the region and socioeconomic status, which contributes to the difficulty of getting a better portrait of the clinical condition. In low-income regions and tropical countries, AKI is frequently attributed to diarrhea, infections, nephrotoxins, as well as obstetric complications. As opposed to the situation in high-income countries, access to basic care in LMICs is limited by economic constraints, and treatment is often delayed due to late presentation and recognition of the condition, which contribute to worse outcomes. In addition, dialysis is often not available or must be
\end{abstract}

paid by patients, which further restricts its use. Key Messages: There are great disparities in the epidemiology of AKI between Western high-income countries and Western LMICs. In LMICs, education and training programs should increase the public awareness of AKI and improve preventive and basic treatments to improve AKI outcomes. Facts from East and West: (1) More than $90 \%$ of the patients recruited in AKI studies using KDIGO-equivalent criteria originate from North America, Europe, or Oceania, although these regions represent less than a fifth of the global population. However, the pooled incidence of AKI in hospitalized patients reaches $20 \%$ globally with moderate variance between regions. (2) The lower incidence rates observed in Asian countries (except Japan) may be due to a poorer recognition rate, for instance because of less systematically performed serum creatinine tests. (3) AKI patients in South and Southeastern Asia are younger than in East Asia and Western countries and present with fewer comorbidities. (4) Asian countries (and to a certain extent Latin America) face specific challenges that lead to AKI: nephrotoxicity of traditional herbal and less strictly regulated nonprescription medicines, environmental toxins (snake, bee, and wasp venoms), and tropical infectious diseases (malaria and leptospirosis). A higher incidence and less efficient management of natural disasters (particularly earthquakes) are also causes of AKI that Western countries are less

For acute kidney injury in Asia, see Yang, Kidney Dis 2016;2:95-102.

\section{KARGER}

E-Mail karger@karger.com

www.karger.com/kdd
C 2016 S. Karger AG, Basel

2296-9381/16/0023-0103\$39.50/0
Ravindra L. Mehta, MD

200 W Arbor Drive

Mail Code 8342

San Diego, CA 92103 (USA)

E-Mail rmehta@ucsd.edu 
likely to encounter. (5) The incidence of obstetric AKI decreased globally together with an improvement in socioeconomic levels particularly in China and India in the last decades. However, antenatal care and abortion management must be improved to reduce AKI in women, particularly in rural areas. (6) Earlier nephrology referral and better access to peritoneal dialysis should improve the outcome of AKI patients.

(c) 2016 S. Karger AG, Basel

\section{Introduction}

Acute kidney injury (AKI) is frequent, occurring in $21 \%$ of hospital admissions worldwide [1], and is associated with increased morbidity, mortality, and cost $[2,3]$. The epidemiology of AKI mainly derives from studies performed in Western high-income countries [1,4], as low-income and middle-income countries (LMICs) do not necessarily have the infrastructure to collect and report their data.

A worldwide meta-analysis published in 2013 using KDIGO-equivalent criteria for AKI diagnosis $[4,5]$ has shown that out of 147 AKI studies performed between 2004 and 2012, 41\% originated from Europe and 43\% from North America [4]. Very limited data are available from LMICs located in South and Central America [1]. In these regions, only 3\% originated from South America and none from Central America [1, 4]. Moreover, almost all studies from South America were performed in critically ill patients in Brazil, further limiting comparisons between countries $[1,4]$. Most other reports from LMICs were performed in a single center and described AKI due to a single disease without reference to the underlying population [1]. Data on community-acquired AKI in rural areas are therefore missing [1]. In addition, the size of the studies varied widely between regions. Although $85 \%$ of the world population resides in LMICs, studies from North America included a total of 1,843,243 patients, those from Europe 917,492 patients, and those from South America 3,046 patients only [4].

As opposed to previous results, the most recent metaanalysis on worldwide AKI showed that the pooled incidence in LMICs around the world is now close to that of developed countries [1]. This may be due to an increased awareness of AKI, increased diagnostic capacities and accessibility of services, and the use of comparable definitions (KDIGO or KDIGO-equivalent) [1]. However, there are still gaps in the knowledge about the factors affecting AKI incidence and outcomes worldwide. Varia- tions in climate, ethnicity, culture, and socioeconomic status affect the etiology and management of AKI, which contributes to influence mortality and nonrecovery of renal function. However, these variations and their effect on outcomes have not been properly quantified. The current review focuses on the epidemiology, etiology and patterns, recognition and management, as well as outcomes of AKI in Western countries (table 1).

\section{Epidemiology of AKI in Western Countries}

In recent meta-analyses $[1,4]$, the pooled incidence of AKI in hospitalized patients using a KDIGO-equivalent AKI definition was $22.3 \%$ in North America, $31.0 \%$ in South America, and 16.9\% in Australia and New Zealand, and varied between 19.3 and 25.2\% in Europe [1]. As seen in Asia, most of the publications still came from large academic hospitals and included critically ill and/or septic patients, or those who underwent cardiac surgery or who received nephrotoxins. Consequently, the AKI incidence in community hospitals and rural areas is unknown $[1,4]$.

The incidence of AKI is increasing [6-8] and may double over the next decade $[9,10]$. AKI is increasing mainly in patients with acute illness and possibly in those undergoing major surgery, which may be related to improved ascertainment in administrative databases and higher sensitivity of diagnostic criteria, older populations with additional comorbidities and the occurrence of more frequent modifiable risk factors, such as sepsis, administration of iodinated contrast, and exposure to nephrotoxins [8]. In a recent multivariate logistic regression to identify diagnoses and procedures that may affect the increased risk of dialysis-requiring AKI in the USA, diagnoses such as sepsis, hypertension, respiratory failure, hemorrhagic disorders, shock, and liver disease were associated with more frequent dialyses but not surgeries or other procedures [11].

\section{Community-Acquired AKI and Hospital-Acquired} AKI (General Hospital Wards)

There are very limited reports on community-acquired AKI $[6,12]$. The worldwide meta-analysis on AKI previously mentioned has shown that only 7 (5\%) of 147 studies focused on community-acquired AKI [4]. According to these studies, the overall incidence of AKI was $8.3 \%$ [4]. One study has quantified the incidence of nondialysis-requiring and dialysis-requiring AKI among members of a large integrated health-care delivery system in California [6]. Between 1996 and 2003, the incidence 
Table 1. Differences in the epidemiology and outcomes of AKI between high- and low-income Western countries

\begin{tabular}{lll}
\hline & High income & Low income \\
\hline Incidence & Increasing & Increasing \\
\hline Etiologies & $\begin{array}{l}\text { Sepsis, hypovolemia, } \\
\text { drugs, and ischemia }\end{array}$ & $\begin{array}{l}\text { Similar etiologies in urban } \\
\text { areas; more diarrhea, tropical } \\
\text { diseases, animal venoms, and } \\
\text { obstetric complications in } \\
\text { rural areas }\end{array}$ \\
\hline
\end{tabular}

\begin{tabular}{lll}
\hline $\begin{array}{l}\text { Types of } \\
\text { population }\end{array}$ & $\begin{array}{l}\text { Often older patients } \\
\text { with multiple } \\
\text { comorbidities }\end{array}$ & $\begin{array}{l}\text { Similar populations in urban } \\
\text { areas; younger populations in } \\
\text { rural areas }\end{array}$ \\
\hline Location & $\begin{array}{l}\text { Often in intensive care } \\
\text { units }\end{array}$ & $\begin{array}{l}\text { More often community } \\
\text { acquired }\end{array}$ \\
\hline $\begin{array}{l}\text { Number of } \\
\text { organs affected }\end{array}$ & $\begin{array}{l}\text { Often associated with } \\
\text { multiorgan failure }\end{array}$ & $\begin{array}{l}\text { More often a single-organ } \\
\text { disease in rural areas }\end{array}$ \\
\hline $\begin{array}{l}\text { Availability } \\
\text { of dialysis }\end{array}$ & $\begin{array}{l}\text { Not a concern to most } \\
\text { patients }\end{array}$ & Major issue \\
\hline Mortality & $\begin{array}{l}\text { Overall decreasing; } \\
\text { higher mortality if } \\
\text { associated with } \\
\text { multiorgan failure }\end{array}$ & $\begin{array}{l}\text { Overall decreasing; mortality } \\
\text { seems higher than in high- } \\
\text { income countries for similar } \\
\text { disease severity }\end{array}$ \\
\hline Cost & Very high & Depending on resources \\
\hline Prevention & $\begin{array}{l}\text { Avoidance of } \\
\text { nephrotoxins, more } \\
\text { difficult to prevent }\end{array}$ & $\begin{array}{l}\text { Importance of timely } \\
\text { hydration and treatment of } \\
\text { infections }\end{array}$ \\
\hline Report & Excellent data & Limited data \\
\hline
\end{tabular}

Adapted from Mehta et al. [1].

of non-dialysis-requiring AKI increased from 322.7 to 522.4 per 100,000 person-years and that of dialysis-requiring AKI from 19.5 to 29.5 per 100,000 person-years [6]. In another European study performed 20 years ago, the overall incidence of AKI was 209 cases per million population, and AKI occurred in 52\% of patients at hospital admission and later on during the hospital stay in the remaining patients (48\%) [12].

Hospital-acquired AKI outside intensive care units is also not well described. In the meta-analysis, 50 (34\%) AKI studies were either hospital acquired or unspecified [4], and the AKI incidence was 20.7\% [4]. No further characterization was available. A recent large study in 10 hospitals in England and Scotland identified AKI in 18\% of patients, which is consistent with results from the worldwide meta-analysis [13]. In LMICs, insufficient monitoring of serum creatinine in hospitalized patients may also miss a significant proportion of patients with the condition.

$\mathrm{AKI}$ in Western Countries

\section{Intensive Care Unit}

AKI is well described in critically ill patients. As reported in one of the two worldwide meta-analyses, $24 \%$ of studies were performed in critically ill patients, $29 \%$ in cardiac surgery patients, and 3\% in patients who experienced trauma [4]. Therefore, $56 \%$ of all AKI studies included patients at least transiting in the intensive care unit. The worldwide pooled AKI incidence in critically ill patients was $30.9 \%$ [4]. In comparison, $24.3 \%$ of patients undergoing cardiac surgery or $19.9 \%$ of trauma patients had AKI. However, there are large variations in the incidence and severity of AKI in similar settings. For example, studies have shown AKI rates between 12 and $45 \%$ following cardiac surgery $[14,15]$. These differences may be related to variations in comorbidities and practice patterns.

\section{Causes and Patterns of AKI in Western Countries}

AKI can be caused by multiple different insults, and patterns of AKI are different across the world [1]. In highincome countries, patients are older and have more comorbidities, such as diabetes mellitus, cardiovascular disease, malignancy, and possibly chronic kidney disease (CKD) $[1,16]$. The most common causes for AKI in highincome countries are sepsis, hypovolemia, drugs, and ischemia $[1,16,17]$, and AKI is often associated with other acute organ failures $[16,17]$.

AKI caused by sepsis, hypovolemia, drugs, and ischemia also occurs in LMICs, mainly in urban areas. Other causes of AKI, such as glomerulonephritis and acute interstitial nephritis, are more often diagnosed in intensive care units in LMICs than in high-income countries [16]. However, it is unclear whether these represent real differences or whether they reflect variations in practice patterns regarding kidney biopsies. In one multicenter international study on AKI in critically ill patients, no kidney biopsy was done in developed countries, while $5.2 \%$ of patients from emerging countries had a biopsy performed [16].

In LMICs, the etiologies of AKI vary depending on the region [1]. In tertiary hospitals in urban areas, causes are similar as in high-income countries [18] but may also include tropical infectious diseases such as malaria, leptospirosis, and dengue $[19,20]$. In rural areas, AKI is often attributed to diarrhea, tropical infectious diseases, animal venoms, natural medicines and dyes, and obstetric complications including septic abortion [1,21, 22]. Unfortunately, these conditions often affect younger people without comorbidities. 
Tropical Infectious Diseases Causing AKI

Malaria is a common cause of AKI in tropic communities mainly attributed to Plasmodium falciparum and less often to Plasmodium vivax infection. Reports on AKI and malaria from Western countries are very limited, but the incidence is increasing in Africa and Asia [2]. Following P. falciparum infection, AKI will occur in $1-4 \%$ of patients but may occur in up to $60 \%$ depending on the region [2]. Risk factors for AKI are not well characterized $[23,24]$. Prompt initiation of antimalarial drugs, surveillance of kidney function, and initiation of dialysis if required can contribute to improve survival and facilitate renal recovery [23].

Leptospirosis, a spirochetal zoonosis, is often misdiagnosed as another disease such as dengue in South America despite its resurgence [25]. In urban Brazil, outbreaks of leptospirosis often follow heavy rain and flooding, as humans get infected either by exposure to contaminated water from infected animal urine or occupational contact with infected animal tissue. Up to $80 \%$ of infected patients will develop AKI [26], and dialysis has been required in $38 \%$ of adults suffering from the infection in a Brazilian cohort [26]. Early administration of antibiotics may reduce the likelihood of progression to severe disease for some patients [27].

Dengue is a frequent viral infection transmitted by a mosquito bite that represents a major threat to public health worldwide according to experts in the field [28]. AKI is a serious complication of dengue, and its frequency is not well characterized but seems to occur in 1-13\% of patients [28]. In a retrospective study from a tertiary infectious diseases hospital in Brazil, $4 \%$ of critically ill patients with AKI were affected by dengue [20]. Human immunodeficiency virus (30\%), tuberculosis $(12 \%)$, and leptospirosis (11\%) occurred more frequently than dengue [20]. Treatment for dengue is mainly supportive, and although rhabdomyolysis is rarely associated with dengue, monitoring of serum creatine kinase levels is required to promptly diagnose and treat this condition which can further contribute to AKI. The pathophysiology of rhabdomyolysis in dengue may be caused by direct viral invasion or be mediated by myotoxic cytokines, such as tumor necrosis factor [28].

\section{Environmental Nephrotoxin-Induced AKI}

In a tertiary care center in Brazil, out of 276 victims of snakebites, AKI was observed in 15\% [29]. These patients were young ( $43 \pm 20$ years). A longer time having elapsed between the snakebite and medical care and between the snakebite and antivenom was associated with AKI. Dialy- sis was required in $30 \%$ of patients, and renal recovery was present in $55 \%$ of patients at discharge.

\section{AKI in Pregnancy}

$\mathrm{AKI}$ in pregnancy (P-AKI) is a cause of significant fetomaternal mortality and morbidity, mainly in developing countries [30]. Hypertensive disorders of pregnancy [preeclampsia/eclampsia or hemolysis, elevated liver enzymes, and low platelet count syndrome (HELLP)] are the leading causes of P-AKI worldwide [30]. The incidence of P-AKI has declined in developed countries over the last three decades due to the decreased incidence in septic abortions and a better management of hypertensive disorders of pregnancy [30]. However, a recent large Canadian study has shown that rates of obstetric AKI increased from 1.7 to 2.7 per 10,000 deliveries between 2004 and 2010 (61\% increase, 95\% CI 24-110) [31]. The increase was related to hypertensive disorders, especially gestational hypertension with significant proteinuria (adjusted increase $171 \%, 95 \%$ CI 71-329\%). In developing countries, the incidence of $\mathrm{P}-\mathrm{AKI}$ remains high but seems to decrease [30] and is more often attributed to septic abortions, poor follow-up of pregnancy with limited screening, and late referral of hypertensive complications of pregnancy [30]. Significant mortality is associated with P-AKI. As shown in a series of 55 patients from a Brazilian hospital, maternal mortality was 31\% [32].

\section{Recognition and Management of AKI in Western Countries}

\section{Recognition}

Even in developed countries where resources are easily available for AKI diagnosis, the recognition of AKI can be problematic. A recent assessment of the quality of care in the UK found that AKI was not recognized in $24 \%$ of 1,577 patients [33]. Moreover, advisers from the UK National Confidential Enquiry into Patient Outcome and Death (NCEPOD) study found that $43 \%$ of patients had an improper delay in the diagnosis of posthospitalization AKI [34].

There are controversial data on the effect of electronic alert protocols to detect AKI and improve outcomes. Korean investigators reported on an electronic AKI alert protocol warning physicians and recommending prophylactic measures to prevent contrast-induced AKI when an investigation using contrast was ordered for patients with an estimated glomerular filtration rate of 60 $\mathrm{ml} / \mathrm{min} / 1.73 \mathrm{~m}^{2}$ [35]. This observational study included 
463 patients, and the measure increased the use of prophylaxis from 25 to $55 \%(\mathrm{p}<0.001)$ and lowered the incidence of contrast-induced AKI (10 to 3\%, $\mathrm{p}=0.02$ ) [35]. In a prospective observational study from Belgium including 951 critically ill patients, an electronic AKI alert protocol reduced the time to therapeutic intervention and may have helped to normalize kidney function within hours after an AKI alert $(p=0.05)$ [36]. However, in a single-blinded randomized-controlled trial from the USA including 2,392 hospitalized patients, maximum changes in creatinine, dialysis, and death at 7 days did not differ between alert and usual care groups $(p=0.88)$ [37]. Reasons explaining these discrepant results are not fully understood. It is possible that AKI alerts in critically ill patients were more frequently associated with changes in therapeutic interventions than in hospitalized patients taken care of by physicians not necessarily used to managing AKI. Additionally, the methods of AKI detection and the methods by which results are communicated need to be delineated, as these influence effectiveness [38]. Finally, in developing countries, a significant proportion of hospitalized patients may not have sufficient serum creatinine testing to assess AKI, as shown in Asia.

\section{Management}

AKI is often preventable and treatable with timely interventions such as volume repletion and treatment of associated infections [8]. However, the management of AKI is highly variable even in countries with available and accessible resources. Guidelines for AKI management are not universally available or applied [39-41]. In LMICs, the paucity of infrastructure and resources to treat AKI and its complications represent major issues.

In 2013, the International Society of Nephrology instituted the 0by 25 initiative [1], aiming to prevent any death from untreated AKI in low-resource regions by 2025 . This statement was based on the premise that 'the ability to provide lifesaving treatments for AKI provides a compelling argument to consider therapy for AKI as much of a basic right as it is to give antiretroviral drugs to treat human immunodeficiency virus in low-resource regions, especially because care needs only be given for a short period of time in most patients'.

\section{Renal Replacement Therapy}

The overall proportion of patients with AKI who needed dialysis in KDIGO-defined studies is $11 \%$ [1]. It has been estimated that $5 \%$ of critically ill patients will require dialysis [42]. If dialysis is unavailable as for most people in LMICs, death ensues because of fluid overload, hyper- kalemia, and uremic toxins accumulation. In LMICs, there are often no dialysis facilities or no health insurance, so that patients cannot afford dialysis or can only pay for a short period until their financial resources are exhausted [1]. Dialysis availability can vary widely even between different areas of the same country. The use of peritoneal dialysis may facilitate access to dialysis in some parts of the world. Several studies mainly from Brazil have shown that peritoneal dialysis can provide similar outcomes to other dialysis modalities in AKI [43-45].

\section{Renal Referral}

Delayed or absent nephrology referral is associated with a higher mortality, dialysis dependence, and length of hospital stay [46-48]. However, given the incidence of AKI, there is an insufficient number of nephrologists to care for all these patients. Therefore, it is essential to properly train primary care physicians to raise AKI awareness, enable prompt identification of patients with AKI, and provide practical management of AKI including nephrology referral if required, especially in LMICs.

\section{Follow-Up}

In an ideal world, all patients who survive episodes of AKI should have their kidney function monitored for at least 3 months and possibly longer after hospital discharge. A recent observational study also showed that nephrology follow-up within 90 days of discharge was associated with a lower mortality [49]. However, most patients do not have long-term follow-up of kidney function, and many never see a nephrologist, even in developed countries with universal coverage by national health systems [49]. This may also affect long-term deterioration of renal function and progression to $\mathrm{CKD}$.

\section{Outcomes}

The course of AKI varies with its setting, and the severity and duration of AKI affect dialysis requirement, recovery of renal function, and survival. However, it is unclear how exactly variations in processes of care influence outcomes.

\section{Mortality}

AKI has been independently associated with an increased risk of adverse outcomes, including death [50]. In the most recent meta-analysis, the overall AKI mortality was just $21 \%$, probably due to the predominance of AKI stage 1 [1]. Indeed, the mortality rates increase with AKI 
severity, from $15.9 \%$ in stage 1 to $47.8 \%$ in stage 3 [4] and 49.3\% in dialysis-requiring AKI [4]. Mortality is also higher in emerging compared to developed countries, possibly because of more severe AKI due to late presentation at care facilities or inadequate care [1]. In South America, the pooled mortality was $33.4 \%$, while it was $16.6 \%$ in North America and ranged from 17.2 to $26.1 \%$ in Europe [4].

Encouragingly, mortality rates attributed to AKI have decreased, at least in high-income countries $[4,7,51]$. In dialysis-requiring AKI, one large study has shown that the 90 -day mortality declined from $50 \%$ in $1996-2000$ to $45 \% 10$ years later [7]. Another study found that in-hospital mortality declined from 41.3 to $28.1 \%$ between 1988 and 2002 in patients requiring dialysis, and from 40.4 to $20.3 \%$ in all AKI patients [51]. This decrease in mortality may be related to more frequent testing of serum creatinine, increased use of preventive strategies, and avoidance of nephrotoxins including starches [52-54], as well as better patient management, such as earlier initiation of dialysis and avoidance of fluid accumulation [55].

\section{Kidney Outcomes}

AKI also affects long-term kidney function, as shown in large studies from the USA and Europe. Since followup care is less frequent and longitudinal databases are rare in LMICs, the epidemiology of CKD after AKI is unknown in these countries. For patients who survive hospitalization with acute dialysis, data from high-income countries showed that $5-20 \%$ will remain on dialysis at hospital discharge [56]. For patients who recover from AKI within 10 days, the risk of developing stage $3 \mathrm{CKD}$ increases 2 -fold by 1 year [57]. In addition, the risk of $\mathrm{CKD}$ increases with the number of AKI episodes [58]. It has been estimated that following AKI, the risk of developing CKD increases 8- to 9-fold and for end-stage renal disease 3 -fold over the following years [59-62]. CKD and end-stage renal disease both contribute to a poor quality of life and disability in affected patients $[60,63]$.

\section{Costs}

AKI has been independently associated with prolonged hospital lengths of stay [50]. AKI is associated with an up to doubling of hospital costs, independent of other factors $[64,65]$. In the USA, a conservative estimate of health-care costs attributed to AKI exceeded USD 10 billion per year 10 years ago [50]. A recent English study showed that the estimated annual cost of AKI care was more than USD 1.7 billion [66]. The use of different dialysis modalities can affect AKI-associated costs. Perito- neal dialysis is the less expensive option. The use of intermittent hemodialysis or sustained low-efficiency daily dialysis rather than continuous renal replacement therapy could also reduce costs [67-69]. However, if continuous renal replacement therapy improves renal recovery among survivors, it may be worth additional expenses [67]. However, the effect of dialysis modalities on renal recovery is still uncertain.

\section{Future Perspectives}

There are great disparities in the epidemiology, recognition, management, and outcomes of AKI between Western high-income countries and Western LMICs. Limited data exist on the incidence and outcomes of AKI in community hospitals and rural areas, even in high-income countries. Worldwide, the incidence of AKI is increasing, but AKI-associated mortality is declining. In high-income countries, education programs should focus on preventing exposure to nephrotoxins, if feasible, and provide adequate management in a timely manner. In LMICs and high-income countries, education and training programs should increase the public awareness of AKI, as highlighted by the 0by 25 initiative [1]. Also, education should focus on improving preventive and basic treatments to ameliorate AKI outcomes. Specifically, education programs should focus on the identification of high-risk patients, exposures causing AKI, tests to diagnose AKI, interventions to correct reversible factors, recognition of the need for dialysis, and referral to a nephrologist if needed. These programs need to be tailored to the peculiarities of the different countries and areas, considering health-care resources, personnel, and infrastructure to efficiently improve AKI outcomes.

\section{Acknowledgements}

This work was supported by the UAB-UCSD O'Brien Center for Acute Kidney Injury (National Institutes of Health, National Institute of Diabetes and Digestive and Kidney Disease grant DK079337). J.B. is a scholar of the Fonds de la Recherche du Québec - Santé.

\section{Conflict of Interest Statement}

The authors declare no conflicts of interest. 


\section{References}

-1 Mehta RL, Cerda J, Burdmann EA, Tonelli M, Garcia-Garcia G, Jha V, Susantitaphong P, Rocco M, Vanholder R, Sever MS, Cruz D, Jaber B, Lameire NH, Lombardi R, Lewington A, Feehally J, Finkelstein F, Levin N, Pannu N, Thomas B, Aronoff-Spencer E, Remuzzi G: International Society of Nephrology's 0by25 initiative for acute kidney injury (zero preventable deaths by 2025): a human rights case for nephrology. Lancet 2015;385:2616-2643.

2 Cerda J, Lameire N, Eggers P, Pannu N, Uchino S, Wang H, Bagga A, Levin A: Epidemiology of acute kidney injury. Clin J Am Soc Nephrol 2008;3:881-886.

-3 Lameire NH, Bagga A, Cruz D, De Maeseneer J, Endre Z, Kellum JA, Liu KD, Mehta RL, Pannu N, Van Biesen W, Vanholder R: Acute kidney injury: an increasing global concern. Lancet 2013;382:170-179.

4 Susantitaphong P, Cruz DN, Cerda J, Abulfaraj M, Alqahtani F, Koulouridis I, Jaber BL; Acute Kidney Injury Advisory Group of the American Society of Nephrology: World incidence of AKI: a meta-analysis. Clin J Am Soc Nephrol 2013;8:1482-1493.

5 Kidney Disease: Improving Global Outcomes (KDIGO) Acute Kidney Injury Work Group: KDIGO clinical practice guideline for acute kidney injury. Kidney Int Suppl 2012;2:1138.

-6 Hsu CY, McCulloch CE, Fan D, Ordonez JD, Chertow GM, Go AS: Community-based incidence of acute renal failure. Kidney Int 2007;72:208-212.

7 Wald R, McArthur E, Adhikari NK, Bagshaw SM, Burns KE, Garg AX, Harel Z, Kitchlu A, Mazer CD, Nash DM, Scales DC, Silver SA, Ray JG, Friedrich JO: Changing incidence and outcomes following dialysis-requiring acute kidney injury among critically ill adults: a population-based cohort study. Am J Kidney Dis 2015;65:870-877.

8 Rewa O, Bagshaw SM: Acute kidney injury epidemiology, outcomes and economics. Nat Rev Nephrol 2014;10:193-207.

$\checkmark 9$ Ali T, Khan I, Simpson W, Prescott G, Townend J, Smith W, Macleod A: Incidence and outcomes in acute kidney injury: a comprehensive population-based study. J Am Soc Nephrol 2007;18:1292-1298.

10 Goldstein SL, Jaber BL, Faubel S, Chawla LS; Acute Kidney Injury Advisory Group of American Society of Nephrology: AKI transition of care: a potential opportunity to detect and prevent CKD. Clin J Am Soc Nephrol 2013;8:476-483.

11 Hsu RK, McCulloch CE, Heung M, Saran R, Shahinian VB, Pavkov ME, Burrows NR, Powe NR, Hsu CY; Centers for Disease Control and Prevention Chronic Kidney Disease Surveillance Team: Exploring potential reasons for the temporal trend in dialysis-requiring AKI in the United States. Clin J Am Soc Nephrol 2016;11:14-20.
12 Liano F, Pascual J: Epidemiology of acute renal failure: a prospective, multicenter, community-based study. Madrid Acute Renal Failure Study Group. Kidney Int 1996;50: 811-818.

13 Finlay S, Bray B, Lewington AJ, Hunter-Rowe $\mathrm{CT}$, Banerjee A, Atkinson JM, Jones MC: Identification of risk factors associated with acute kidney injury in patients admitted to acute medical units. Clin Med 2013;13:233238.

14 Frenette AJ, Bouchard J, Bernier P, Charbonneau A, Nguyen LT, Rioux JP, Troyanov S, Williamson DR: Albumin administration is associated with acute kidney injury in cardiac surgery: a propensity score analysis. Crit Care 2014;18:602.

15 Haase M, Bellomo R, Matalanis G, Calzavacca P, Dragun D, Haase-Fielitz A: A comparison of the RIFLE and Acute Kidney Injury Network classifications for cardiac surgery-associated acute kidney injury: a prospective cohort study. J Thorac Cardiovasc Surg 2009; 138:1370-1376.

16 Bouchard J, Acharya A, Cerda J, Maccariello ER, Madarasu RC, Tolwani AJ, Liang X, Fu P, Liu ZH, Mehta RL: A prospective international multicenter study of AKI in the intensive care unit. Clin J Am Soc Nephrol 2015;10: 1324-1331.

17 Hoste EA, Bagshaw SM, Bellomo R, Cely CM, Colman R, Cruz DN, Edipidis K, Forni LG, Gomersall CD, Govil D, Honore PM, JoannesBoyau O, Joannidis M, Korhonen AM, Lavrentieva A, Mehta RL, Palevsky P, Roessler E, Ronco C, Uchino S, Vazquez JA, Vidal Andrade E, Webb S, Kellum JA: Epidemiology of acute kidney injury in critically ill patients: the multinational AKI-EPI study. Intensive Care Med 2015;41:1411-1423.

18 Santos WJ, Zanetta DM, Pires AC, Lobo SM, Lima EQ, Burdmann EA: Patients with ischaemic, mixed and nephrotoxic acute tubular necrosis in the intensive care unit - a homogeneous population? Crit Care 2006;10:R68.

19 Saravu K, Rishikesh K, Parikh CR: Risk factors and outcomes stratified by severity of acute kidney injury in malaria. PLoS One 2014;9:e90419.

20 Daher Ede F, Junior Silva GB, Vieira AP, Souza JB, Falcao Fdos S, Costa CR, Fernandes AA, Lima RS: Acute kidney injury in a tropical country: a cohort study of 253 patients in an infectious diseases intensive care unit. Rev Soc Bras Med Trop 2014;47:86-89.

21 Cerda J, Bagga A, Kher V, Chakravarthi RM: The contrasting characteristics of acute kidney injury in developed and developing countries. Nat Clin Pract Nephrol 2008;4:138-153.

22 Lombardi R, Yu L, Younes-Ibrahim M, Schor N, Burdmann EA: Epidemiology of acute kidney injury in Latin America. Semin Nephrol 2008;28:320-329.
23 Vannaphan S, Walters N, Saengnedsawang T, Tangpukdee N, Kham-In P, Klubprasit M, Wilairatana P, Looareesuwan S: Factors associated with acute renal failure in severe falciparum [corrected] malaria patients. Southeast Asian J Trop Med Public Health 2010;41: 1042-1047.

24 Koopmans LC, van Wolfswinkel ME, Hesselink DA, Hoorn EJ, Koelewijn R, van Hellemond JJ, van Genderen PJ: Acute kidney injury in imported Plasmodium falciparum malaria. Malar J 2015;14:523.

25 Cruz LS, Vargas R, Lopes AA: Leptospirosis: a worldwide resurgent zoonosis and important cause of acute renal failure and death in developing nations. Ethn Dis 2009;19(1 suppl 1):S1-37-41.

26 Daher EF, Vieira AP, Jacinto CN, Lima RS, Girao MM, Fernandes AT, Neto RJ, Silva GBJ: Differences among children, adolescents and adults with severe leptospirosis: a comparative analysis. Indian J Nephrol 2014;24:166-170.

27 Tubiana S, Mikulski M, Becam J, Lacassin F, Lefevre P, Gourinat AC, Goarant C, D'Ortenzio E: Risk factors and predictors of severe leptospirosis in New Caledonia. PLoS Negl Trop Dis 2013;7:e1991.

28 Oliveira JF, Burdmann EA: Dengue-associated acute kidney injury. Clin Kidney J 2015;8: 681-685.

29 Albuquerque PL, Silva GB Jr, Jacinto CN, Lima JB, Lima CB, Amaral YS, Veras Mdo S, Mota RM, Daher EF: Acute kidney injury after snakebite accident treated in a Brazilian tertiary care centre. Nephrology 2014;19: 764-770.

30 Fakhouri F, Vercel C, Fremeaux-Bacchi V: Obstetric nephrology: AKI and thrombotic microangiopathies in pregnancy. Clin J Am Soc Nephrol 2012;7:2100-2106.

31 Mehrabadi A, Liu S, Bartholomew S, Hutcheon JA, Magee LA, Kramer MS, Liston RM, Joseph KS; Canadian Perinatal Surveillance System Public Health Agency of Canada: Hypertensive disorders of pregnancy and the recent increase in obstetric acute renal failure in Canada: population based retrospective cohort study. BMJ 2014;349:g4731.

32 Silva GB Jr, Monteiro FA, Mota RM, Paiva JG, Correia JW, Bezerra Filho JG, Macedo RN, Lima RS, Daher EF: Acute kidney injury requiring dialysis in obstetric patients: a series of 55 cases in Brazil. Arch Gynecol Obstet 2009;279:131-137.

-33 Aitken E, Carruthers C, Gall L, Kerr L, Geddes C, Kingsmore D: Acute kidney injury: outcomes and quality of care. QJM 2013;106: 323-332.

34 Stewart J, Findlay G, Smith N, Kelly K, Mason M: Adding Insult to Injury: A Review of the Care of Patients Who Died in Hospital with a Primary Diagnosis of Acute Kidney Injury (Acute Renal Failure). London, National Confidential Enquiry into Patient Outcome and Death, 2009. 
\$35 Cho A, Lee JE, Yoon JY, Jang HR, Huh W, Kim YG, Kim DJ, Oh HY: Effect of an electronic alert on risk of contrast-induced acute kidney injury in hospitalized patients undergoing computed tomography. Am J Kidney Dis 2012;60:74-81.

- 36 Colpaert K, Hoste EA, Steurbaut K, Benoit D, Van Hoecke S, De Turck F, Decruyenaere J: Impact of real-time electronic alerting of acute kidney injury on therapeutic intervention and progression of RIFLE class. Crit Care Med 2012;40:1164-1170.

- 37 Wilson FP, Shashaty M, Testani J, Aqeel I, Borovskiy Y, Ellenberg SS, Feldman HI, Fernandez H, Gitelman Y, Lin J, Negoianu D, Parikh CR, Reese PP, Urbani R, Fuchs B: Automated, electronic alerts for acute kidney injury: a single-blind, parallel-group, randomised controlled trial. Lancet 2015;385: 1966-1974.

- 38 Horne KL, Selby NM: Recent developments in electronic alerts for acute kidney injury. Curr Opin Crit Care 2015;21:479-484.

-39 Ad-hoc working group of ERBP; Fliser D, Laville M, Covic A, Fouque D, Vanholder R, Juillard L, Van Biesen W: A European Renal Best Practice (ERBP) position statement on the Kidney Disease Improving Global Outcomes (KDIGO) clinical practice guidelines on acute kidney injury: part 1: definitions, conservative management and contrast-induced nephropathy. Nephrol Dial Transplant 2012;27:4263-4272.

40 James M, Bouchard J, Ho J, Klarenbach S, LaFrance JP, Rigatto C, Wald R, Zappitelli M, Pannu N: Canadian Society of Nephrology commentary on the 2012 KDIGO clinical practice guideline for acute kidney injury. Am J Kidney Dis 2013;61:673-685.

-41 Palevsky PM, Liu KD, Brophy PD, Chawla LS, Parikh CR, Thakar CV, Tolwani AJ, Waikar SS, Weisbord SD: KDOQI US commentary on the 2012 KDIGO clinical practice guideline for acute kidney injury. Am J Kidney Dis 2013;61:649-672.

-42 Uchino S, Kellum JA, Bellomo R, Doig GS, Morimatsu H, Morgera S, Schetz M, Tan I, Bouman C, Macedo E, Gibney N, Tolwani A, Ronco C: Acute renal failure in critically ill patients: a multinational, multicenter study. JAMA 2005;294:813-818.

-43 Ponce D, Berbel MN, Abrao JM, Goes CR, Balbi AL: A randomized clinical trial of high volume peritoneal dialysis versus extended daily hemodialysis for acute kidney injury patients. Int Urol Nephrol 2013;45:869-878.

44 Gabriel DP, Caramori JT, Martim LC, Barretti P, Balbi AL: High volume peritoneal dialysis vs daily hemodialysis: a randomized, controlled trial in patients with acute kidney injury. Kidney Int Suppl 2008;108:S87-S93.
45 Chionh CY, Soni SS, Finkelstein FO, Ronco C, Cruz DN: Use of peritoneal dialysis in AKI: a systematic review. Clin J Am Soc Nephrol 2013;8:1649-1660.

-46 Mehta RL, McDonald B, Gabbai F, Pahl M, Farkas A, Pascual MT, Zhuang S, Kaplan RM, Chertow GM: Nephrology consultation in acute renal failure: does timing matter? Am J Med 2002;113:456-461.

47 Costa e Silva VT, Liano F, Muriel A, Diez R, de Castro I, Yu L: Nephrology referral and outcomes in critically ill acute kidney injury patients. PLoS One 2013;8:e70482.

48 Ponce D, Zorzenon Cde P, dos Santos NY, Balbi AL: Early nephrology consultation can have an impact on outcome of acute kidney injury patients. Nephrol Dial Transplant 2011;26:3202-3206.

49 Harel Z, Wald R, Bargman JM, Mamdani M, Etchells E, Garg AX, Ray JG, Luo J, Li P, Quinn RR, Forster A, Perl J, Bell CM: Nephrologist follow-up improves all-cause mortality of severe acute kidney injury survivors. Kidney Int 2013;83:901-908.

50 Chertow GM, Burdick E, Honour M, Bonventre JV, Bates DW: Acute kidney injury, mortality, length of stay, and costs in hospitalized patients. J Am Soc Nephrol 2005; 16: 3365-3370.

51 Waikar SS, Curhan GC, Wald R, McCarthy EP, Chertow GM: Declining mortality in patients with acute renal failure, 1988 to 2002 . Am Soc Nephrol 2006;17:1143-1150.

52 Paquette F, Bernier-Jean A, Brunette V, Ammann $\mathrm{H}$, Lavergne V, Pichette V, Troyanov S, Bouchard J: Acute kidney injury and renal recovery with the use of aminoglycosides: a large retrospective study. Nephron 2015;131: 153-160.

53 Schortgen F, Lacherade JC, Bruneel F, Cattaneo I, Hemery F, Lemaire F, Brochard L: Effects of hydroxyethylstarch and gelatin on renal function in severe sepsis: a multicentre randomised study. Lancet 2001;357:911-916.

54 Myburgh JA, Finfer S, Bellomo R, Billot L, Cass A, Gattas D, Glass P, Lipman J, Liu B, McArthur C, McGuinness S, Rajbhandari D, Taylor CB, Webb SA; CHEST Investigators; Australian and New Zealand Intensive Care Society Clinical Trials Group: Hydroxyethyl starch or saline for fluid resuscitation in intensive care. N Engl J Med 2012;367:19011911.

55 Bouchard J, Soroko SB, Chertow GM, Himmelfarb J, Ikizler TA, Paganini EP, Mehta RL: Fluid accumulation, survival and recovery of kidney function in critically ill patients with acute kidney injury. Kidney Int 2009;76:422427.

56 Hoste EA, Schurgers M: Epidemiology of acute kidney injury: how big is the problem? Crit Care Med 2008;36:S146-S151.
57 Heung M, Steffick DE, Zivin K, Gillespie BW, Banerjee T, Hsu CY, Powe NR, Pavkov ME, Williams DE, Saran R, Shahinian VB; Centers for Disease Control and Prevention CKD Surveillance Team: Acute kidney injury recovery pattern and subsequent risk of CKD: an analysis of Veterans Health Administration data. Am J Kidney Dis 2015, Epub ahead of print.

58 Thakar CV, Christianson A, Himmelfarb J, Leonard AC: Acute kidney injury episodes and chronic kidney disease risk in diabetes mellitus. Clin J Am Soc Nephrol 2011;6:25672572.

59 Chawla LS, Amdur RL, Amodeo S, Kimmel PL, Palant CE: The severity of acute kidney injury predicts progression to chronic kidney disease. Kidney Int 2011;79:1361-1369.

60 Coca SG, Singanamala S, Parikh CR: Chronic kidney disease after acute kidney injury: a systematic review and meta-analysis. Kidney Int 2012;81:442-448.

61 Wald R, Quinn RR, Luo J, Li P, Scales DC, Mamdani MM, Ray JG: Chronic dialysis and death among survivors of acute kidney injury requiring dialysis. JAMA 2009;302:11791185.

62 Triverio PA, Martin PY, Romand J, Pugin J, Perneger T, Saudan P: Long-term prognosis after acute kidney injury requiring renal replacement therapy. Nephrol Dial Transplant 2009;24:2186-2189.

63 Chawla LS, Kimmel PL: Acute kidney injury and chronic kidney disease: an integrated clinical syndrome. Kidney Int 2012;82:516-524.

64 Dasta JF, Kane-Gill SL, Durtschi AJ, Pathak DS, Kellum JA: Costs and outcomes of acute kidney injury (AKI) following cardiac surgery. Nephrol Dial Transplant 2008;23:19701974.

65 Brandt MM, Falvo AJ, Rubinfeld IS, Blyden D, Durrani NK, Horst HM: Renal dysfunction in trauma: even a little costs a lot. J Trauma 2007;62:1362-1364.

66 Kerr M, Bedford M, Matthews B, O’Donoghue D: The economic impact of acute kidney injury in England. Nephrol Dial Transplant 2014;29:1362-1368.

67 Manns B, Doig CJ, Lee H, Dean S, Tonelli M, Johnson D, Donaldson C: Cost of acute renal failure requiring dialysis in the intensive care unit: clinical and resource implications of renal recovery. Crit Care Med 2003;31:449-455.

68 Berbece AN, Richardson RM: Sustained lowefficiency dialysis in the ICU: cost, anticoagulation, and solute removal. Kidney Int 2006; 70:963-968.

69 Vitale C, Bagnis C, Marangella M, Belloni G, Lupo M, Spina G, Bondonio P, Ramello A: Cost analysis of blood purification in intensive care units: continuous versus intermittent hemodiafiltration. J Nephrol 2003;16: 572-579. 